\title{
RISK ASSESSMENT PROCEDURE FOR CIVIL AIRPORT
}

\author{
Natalia Distefano ${ }^{1}$, Salvatore Leonardi ${ }^{2}$ \\ 1,2 Department of Civil and Environmental Engineering, University of Catania, Italy \\ Received 7 March 2013; accepted 21 August 2013
}

\begin{abstract}
A practical problem in air transport is how to manage risk and safety. In recent years have been developed special technical and managerial skills to the systematic, forward looking identification and control of hazards throughout the life cycle of a project, program, or activity. Safety Management System (SMS) involves identifying, evaluating, and addressing of hazards or risk. Its sole purpose is to prevent accidents. Safety risk assessment is defined as the systematic identification and evaluation of the risk posed by the complete spectrum of possible accident scenarios. Risk assessment is a tool that supports decision making and as such supports risk management. Risk management comprises the safety optimization of the system, the verification process and risk acceptance, which support airport operations. This paper proposed a quantitative methodology for the risk assessment for a civil airport, which is based on historical data of aircraft accidents, contained in the Aviation Safety Network database, from 1 January 1980 to 31 December 2010.
\end{abstract}

Keywords: airport, aircraft accidents, hazard probability, hazard severity.

\section{Introduction}

During its early years, commercial aviation was a loosely regulated activity characterized by underdeveloped technology; lack of a proper infrastructure; limited oversight; an insufficient understanding of the hazards underlying aviation operations; and production demands incommensurate with the means and resources actually available to meet such demands.

It is hardly surprising that the early days of commercial aviation were characterized by a high frequency of accidents, therefore the overriding priority of the early safety process was the prevention of accidents, and accident investigation was the principal means of prevention.

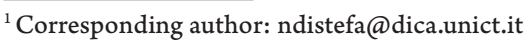

More than $80 \%$ of all aircraft accidents in commercial air transport operations occur at or near an aerodrome. Statistics on accident data show that the greatest number of accidents occurs in flight phases: 'approach and landing' as well as 'standing and taxi' and 'take-off'. This means that the aerodrome, as well as its surroundings, is the area which may see the largest proportion of safety events, varying from hazardous events (e.g. non-stabilized approaches of the runway by an aircraft) to fatal accidents.

Technological improvements (due in no small measure to accident investigation), together with the eventual development of an appropriate infrastructure, led to a gradual but steady decline in the frequency of accidents, as well as an ever-increasing regulatory drive. By the 1950s, aviation was 
becoming (in terms of accidents) one of the safest industries, but also one of the most heavily regulated.

Civil aviation is a complex mosaic of many varied, yet interrelated human, technical, environmental, and organizational factors that affects safety and system performance. Aviation accidents result from multiple contributing factors. Logan (1999) mentioned that operational safety data such as aircraft reliability, flight data records, employee safety reports, enforcement information, inspector investigations or oversight information were also essential to aviation risk analysis.

ICAO recognized the importance of Safety Management System (SMS) and recommended that all contracting states implement the requirement for SMS by November 2005. It relies on an examination of all operational aviation hazards and risks which may impact upon safe operation at the airport. This includes unwritten risks such as human factors, cultural and environmental risks. The potential benefits of SMS are generally recognized throughout the world to the extent that many ICAO nations now require commercial operators to have documented safety management systems. In this regard ICAO emanates the Safety Management Manual (Doc 9859, 2009).

A basic process within the SMS is risk management; it is composed by description of the system, identification of the hazards, assessment of the risk, analysis of the risk, and control of the risk (FAA, 2007).

The objective of risk management is to obtain an understanding of how to access the various levels of hazards and to gain an insight on logical approaches to deal with those hazards. In order to control these risks, risk management techniques must be enforced. The first step of managing risks is to collect data. Once data is collected, accident precursors (hazards) are identified and evaluated. Finally, countermeasures are developed, communicated throughout the organization, and are then implemented in the system.

Hazards can be prioritized according to the probability of an accident occurring, and by the severity of an accident that may occur due to the hazard. In order to prioritize hazards, each hazard must be ranked according to the most severe or the least severe outcomes and to its probability of occurring.

Risk management consists of three essential elements:

- Hazard identification - Identification of undesired or adverse events that can lead to the occurrence of a hazard and the analysis of mechanisms by which these events may occur and cause harm. Both reactive and proactive methods and techniques should be used for hazard identification.

- Risk assessment - Identified hazards are assessed in terms of criticality of their harmful effect and ranked in order of their risk-bearing potential. They are assessed often by experienced personnel, or by utilizing more formal techniques and through analytical expertise. The severity of consequences and the likelihood (frequency) of occurrence of hazards are determined. If the risk is considered acceptable, operation continues without any intervention, if it is not acceptable, risk mitigation process is engaged.

- Risk mitigation - If the risk is considered 
to be unacceptable, then control measures are taken to fortify and increase the level of defenses against that risk or to avoid or remove the risk, if this is economically feasible.

This paper proposes a risk assessment process that employs quantitative methodologies, which are based on historical data of aircraft accidents. In order to determine the probability of the accident it has been adopted a quantitative technique based on the combination of the likely of occurrence of all causes attributed at the accident; differentiating between typical causes the site in question (i.e. presence of snow on the runway, crosswind, etc.) and those independent of the particular site (i.e. outbreak of pneumatic, inadequate crew competence, etc.). In order to define the severity of each accident it has been adopted a quantitative model, which is based on the study of the consequences of aircraft accident from 1 January 1980 to 31 December 2010.

The results of the current study can be used by a broad range of civil aviation organizations for risk assessment and costbenefit studies of actions improvements. Applied to any specific airport, the analysis approach for risk assessment developed in this study will allow users to determine if the risk is relatively high or low and whether there is a need for risk management action.

\section{Methodology}

Risk assessment is the process which associates "hazards" with "risks". When we know the various impacts a hazard may have on our mission and an estimate of how likely it is to occur we can now call the hazard a risk.
Risk is defined as a measure of the threat to safety posed by the accident scenarios and their consequences (Preyssl, 1995).

The modeling approach adopted for the quantitative assessment of the risks associated with runway operations involves several methodological steps which are defined as:

- identification of hazardous conditions and accident scenarios,

- determination of probabilities of the accident identified; and

- definition of consequences of such an accident (fatalities and aircraft damages).

\subsection{Data Description}

One of the key factors that can affect the results of a quantified risk assessment is the quality of the base data used in the analysis.

Historical data is the most appropriate source to utilize as it reflects the actual situation within the industry being assessed. However, such data can be extremely difficult and time consuming to obtain and interpret. One of the principal reasons for such problems relates to the manner in which the information is recorded as it rarely matches the analyst's requirements.

The approach adopted for this study has been to utilize the historical data and supplement any deficiencies with data from generic sources. The failure rate data used in the analysis has been based on the collection and analysis of reported accidents contained in the records of the ANS (Aviation Safety Network) database which is considered according to the following criteria: 
1. Occurrence in the period 1980-2010;

2. Serious incident and incident are excluded;

3. Accidents to helicopters, military aircraft and tourist flights are excluded;

4. Accidents only during final approach, landing, go-around, take-off, initial climb and parking were analyzed; and

5. Sabotage, terrorism and military actions are excluded.
The data used in this study were collected in a database.

Using such criteria, 1749 accidents and serious incidents were selected to compose the information that was used for developing the risk models.

Fig. 1 shows a screenshot of the database, from which it is possible to infer the information collected for each event and the Table 1 summarizes the number of events of the database for flight phase.

\begin{tabular}{|c|c|c|c|c|c|c|c|c|c|c|}
\hline \multicolumn{9}{|c|}{ E a Organizer Deluxe - Database: ToDo-Detailed } & \multicolumn{2}{|c|}{$-0 \times$} \\
\hline \multicolumn{9}{|c|}{ File Prink Search Options Move Advenced Record Updake Hep Web diserver Web } & & \\
\hline \multicolumn{2}{|c|}{ 2t: thryoudir } & \multicolumn{2}{|c|}{ tht None } & \multicolumn{5}{|c|}{ 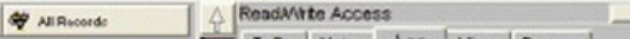 } & \multicolumn{2}{|l|}{ Etark. } \\
\hline TITLE & & & TYPE & MAPORTALCE & $\mathrm{A} T \mathrm{TO} 0 \mid \mathrm{NO}$ & Los Log & Vew $\mid B$ & Browsea & & \\
\hline Date & Location & Phase & Event & Dinamic & Potental cause & $\begin{array}{l}\text { Fatallubas/ } \\
\text { occupants }\end{array}$ & Alrenat & Flight Nature & $\begin{array}{l}\text { Alncret } \\
\text { damage }\end{array}$ & \\
\hline 02 JAN 2010 & $\begin{array}{c}\text { Kinshasa- } \\
\text { ND, II Aipport } \\
\text { (FiH) }\end{array}$ & landing & Landing veer of & 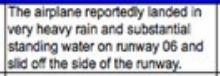 & Heary rain & 012 & Boeing 727 & Cargo & T & \\
\hline 06 JAN 2010 & $\begin{array}{c}\text { Kearney } \\
\text { Regional } \\
\text { Airport NE } \\
\text { (EAR) }\end{array}$ & teke - off & 17 Take-off overun & $\begin{array}{l}\text { The aircrat sustered a loss of } \\
\text { engine power on take-of and } \\
\text { coashed in a wet food plain and } \\
\text { overtumed. }\end{array}$ & Engine fallure & 0.6 & Cessna 2088 & $\begin{array}{l}\text { Non scheduled } \\
\text { passenger }\end{array}$ & $s$ & \\
\hline $08 \operatorname{San} 2010$ & $\begin{array}{c}\text { Val-Eagle } \\
\text { County } \\
\text { Airot Co } \\
\text { (EGE) }\end{array}$ & landing & Landing overrun & 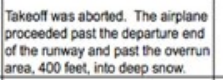 & $\begin{array}{l}\text { Oubrake of } \\
\text { pneumatic }\end{array}$ & on & $\begin{array}{l}\text { Dassaut Falcon } \\
20\end{array}$ & Executve & $s$ & \\
\hline 13 JAN 2010 & $\begin{array}{c}\text { Moba Airpont } \\
\text { (BDV) }\end{array}$ & landing & Landing veer of & $\begin{array}{l}\text { The aircrat undercamiage } \\
\text { collapsed the airplane careered off } \\
\text { the Noba runway }\end{array}$ & Unknown & 0,22 & $\begin{array}{c}\text { de Haviland } \\
\text { Canada DHC \& } \\
102 \\
\end{array}$ & $\begin{array}{c}\text { Non scheduled } \\
\text { passenger }\end{array}$ & s & \\
\hline 24 JAN 2010 & $\mid \begin{array}{c}\text { Mashhad } \\
\text { Airpot (MHO) }\end{array}$ & landing & Overshoot & 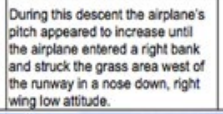 & $\begin{array}{l}\text { Inadequate crew } \\
\text { competence }\end{array}$ & a/170 & Tupolev 15aM & $\begin{array}{l}\text { Scheduled } \\
\text { passenger }\end{array}$ & \multirow{2}{*}{\multicolumn{2}{|c|}{$\stackrel{T}{T} \underset{v}{2}$}} \\
\hline \multirow{2}{*}{\multicolumn{9}{|c|}{ 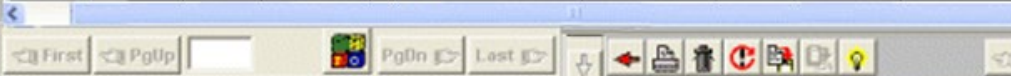 }} & & \\
\hline & & & & PoDn EO Lost $\mathrm{DO}$ & 且 & (4) 争 & De: & 80 & $\boldsymbol{c o s}$ & $33 \frac{1}{2}$ \\
\hline$\rho$ Find & \multicolumn{2}{|c|}{ D) Replace } & NA Options & BPrint $\$$ Table & 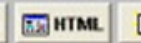 & $\square$ New & ditload & 回 Exit & & \\
\hline Standard & Advanced & & & & & & & & & \\
\hline
\end{tabular}

Fig. 1.

Screenshot of Database

The database includes, for each individual event, the flight phase, the location, the aircraft type, the runway and environmental conditions, the consequences (fatalities, aircraft damage), the flight nature and causal or contributing factors and parameters required to develop the risk models. 
Table 1

Events of Database for Flight Phase

\begin{tabular}{|c|c|c|c|c|c|}
\hline & Parking & Taxi & Take-off & Landing & Total \\
\hline $\mathbf{1 9 8 0 - 1 9 8 4}$ & 35 & 16 & 83 & 170 & 304 \\
\hline $\mathbf{1 9 8 5 - 1 9 8 9}$ & 23 & 15 & 104 & 183 & 325 \\
\hline $\mathbf{1 9 9 0 - 1 9 9 4}$ & 28 & 12 & 108 & 220 & 368 \\
\hline $\mathbf{1 9 9 5 - 1 9 9 9}$ & 21 & 14 & 86 & 240 & 361 \\
\hline $\mathbf{2 0 0 0 - 2 0 0 4}$ & 59 & 35 & 114 & 243 & 451 \\
\hline $\mathbf{2 0 0 5 - 2 0 1 0}$ & 72 & 32 & 118 & 368 & 590 \\
\hline Total & 238 & 124 & 613 & 1424 & 2399 \\
\hline
\end{tabular}

\subsection{Identification of Hazardous Conditions and Accident Scenarios}

A hazard is any condition, object, activity or event with the potential of causing injuries to personnel, damage to equipment or structures, loss of material, or reduction of ability to perform a prescribed function.

In order to identify the hazards inside airport, the scenarios were defined in terms of consequences, not the causes of loss of control.

Looking at absolute values by phase of flights, aerodrome can be seen as the critical location where efforts have to be constantly performed to maintain a uniform high level of safety with the involvement of different types of actors on aerodrome platform.

The purpose of this step in the context of this study was to determine relevant causal factors of aircraft accidents and hazards to aircraft associated with airport operations (e.g., landing, takeoff roll, and associated fault sequences).

The outcome of the hazards identification process has the form of a list of hazards; this hazards logging is useful for subsequent analysis.
It was analyzed the historical data contained in the database created in order to define the aircraft accidents most likely. They are classified into seven scenarios:

- Landing overshoot;

- Landing veer-off;

- Take-off veer-off;

- Landing overrun;

- Take-off overrun;

- Ground collision with other aircraft in landing; and

- Ground collision with other aircraft in take-off.

The definition of each incident type is summarized as follows, consistent with ACRP (2008):

- The overrun accident is an accident during a landing or an aborted takeoff, when the pilot is unable to prevent the aircraft from leaving the paved surface of the runway from its ends. It is a "longitudinal deviation", that is the longitudinal distance traveled beyond the accelerate/stop distance available (for takeoff events), and beyond the landing distance available (for landing events).

- The undershoot accident is a "longitudinal deviation", that is the 
longitudinal distance the aircraft undershoots the intended runway threshold.

- The veer-off accident, both take-off and landing, is a overruns in which the aircraft leaves the side (as opposed to the end) of the runway. It is a "lateral deviation" that is the lateral distance to the extended runway centerline.

- The ground collision with other aircraft is an event where aircraft collide on the runway or while one is on the ground and the other in the air close to the ground, both take-off and landing.

Table 2 shows the number of events of database for accident scenarios and their consequences (fatalities/occupants and aircraft damage). The ranking of aircraft damage consist of tree classifications: Minor (M) if there was no damage to the aircraft; Substantial (S) if there was substantial damages to the aircraft; and Total loss $(\mathrm{T})$ if the aircraft was totally destroyed.

Table 2

Events of Database for Accident Scenarios and their Consequences

\begin{tabular}{|l|c|c|c|c|c|}
\hline \multirow{2}{*}{\multicolumn{1}{c|}{ Accident scenarios }} & \multirow{2}{*}{$\begin{array}{c}\mathbf{N}^{\circ} \\
\text { events }\end{array}$} & Fatalities/occupants & \multicolumn{3}{c|}{ Aircraft damage } \\
\cline { 3 - 6 } & 147 & $124 / 5379$ & 35 & 106 & 6 \\
\hline Landing veer-off & 120 & $208 / 5368$ & 33 & 76 & 11 \\
\hline Landing overrun & 43 & $15 / 1127$ & 12 & 31 & 0 \\
\hline Landing overshoot & 1 & $2 / 3$ & 1 & 0 & 0 \\
\hline Landing collision & 40 & $176 / 715$ & 14 & 25 & 1 \\
\hline Take-off veer-off & 40 & $98 / 987$ & 12 & 28 & 0 \\
\hline Take-off overrun & 5 & $125 / 214$ & 4 & 1 & 0 \\
\hline Take off collision & & & & & S \\
\hline
\end{tabular}

\subsection{The Causes of the Hazards}

The causes of an accident are factors, events, acts, or unsafe conditions which singly, or in combination with other causes, result in the damage or injury that occurred and, if corrected, would have likely prevented or reduced the damage or injury.

Investigating causes of aircraft accidents is difficult because they generally stem from a complex system of mutually dependent, sequential factors (Owen, 1998). The main causes of air accidents can conditionally be classified into: aircraft performance characteristics, runway (taxiway or apron) surface conditions, environmental conditions, human factors (Janic, 2000.)

In order to determine the main causes of each hazard, there were analyzed all events of the database.

In this study the causes were divided in four categories: environmental conditions, runway conditions, aircraft performance characteristics, and human factors.

Table 3 shows, for each type of accident and for each potential cause, the percentage of events of the database in which the cause was present. 
This data covers the whole range from serious incident to accident of the database, therefore they can be considered to be reasonably representative for all civil airports.

\section{Table 3}

Percentage of Accident in Present of the Cause

\begin{tabular}{|c|c|c|c|c|c|c|c|c|}
\hline & & $\begin{array}{l}\text { Landing } \\
\text { short }\end{array}$ & $\begin{array}{l}\text { Landing } \\
\text { Veer off }\end{array}$ & $\begin{array}{l}\text { Landing } \\
\text { overrun }\end{array}$ & \begin{tabular}{|l} 
Take \\
off \\
Veer \\
off \\
\end{tabular} & $\begin{array}{l}\text { Take off } \\
\text { overrun }\end{array}$ & $\begin{array}{l}\text { Ground } \\
\text { collision } \\
\text { in landing }\end{array}$ & $\begin{array}{l}\text { Ground } \\
\text { collision in } \\
\text { take-off }\end{array}$ \\
\hline \multirow{9}{*}{ 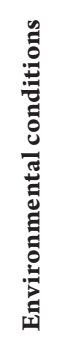 } & Heavy rain & 14,89 & 18,10 & 19,01 & 2,78 & 1,85 & 2,62 & 6,67 \\
\hline & Windshear & - & 1,72 & - & - & - & - & - \\
\hline & Tailwind & - & 1,72 & 4,23 & 8,33 & 1,85 & - & - \\
\hline & \begin{tabular}{|l|} 
Crosswind \\
\end{tabular} & 6,38 & 16,38 & 3,52 & - & - & 7,21 & 6,67 \\
\hline & Bird strike & - & 1,72 & - & - & - & - & - \\
\hline & Fog & - & 5,17 & 5,63 & - & 1,85 & 9,29 & 20 \\
\hline & Snow & 2,13 & 6,03 & 0,70 & 5,56 & - & - & - \\
\hline & Ice & - & - & 2,11 & - & 3,70 & - & - \\
\hline & \begin{tabular}{|l|} 
Vortex shedding \\
\end{tabular} & - & 2,59 & 0,70 & - & - & - & - \\
\hline \multirow{10}{*}{ 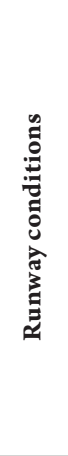 } & Inadequate markers & 2,13 & 0,86 & - & - & - & 1,31 & 6,67 \\
\hline & Loss of runway lights & - & 4,31 & 0,70 & - & - & 7,21 & - \\
\hline & \begin{tabular}{|l|} 
Failure of ILS \\
\end{tabular} & 2,13 & - & - & - & - & - & - \\
\hline & Absence of VASI & 2,13 & - & - & - & - & - & - \\
\hline & High slope of runway & - & 0,86 & - & - & - & - & - \\
\hline & FOD & - & 0,86 & - & 2,78 & - & - & - \\
\hline & Loss of friction & - & - & - & 5,56 & - & - & - \\
\hline & Aquaplaning & - & 6,03 & 18,31 & - & 9,26 & - & - \\
\hline & $\begin{array}{l}\text { Presence of snow on the } \\
\text { runway }\end{array}$ & 2,13 & - & - & - & - & - & - \\
\hline & $\begin{array}{l}\text { Presence of ice on the } \\
\text { runway }\end{array}$ & - & 0,86 & 1,41 & - & 1,85 & - & - \\
\hline \multirow{11}{*}{ 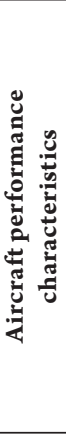 } & Outbreak of pneumatic & - & 6,03 & - & 5,56 & - & - & - \\
\hline & Engine failure & 4,26 & 6,90 & 1,41 & 27,78 & 9,26 & 3,13 & 6,67 \\
\hline & Thrust reverse failure & - & 3,45 & 2,11 & - & 1,85 & - & - \\
\hline & \begin{tabular}{|l|} 
Flap failure \\
\end{tabular} & 2,13 & - & 2,82 & - & - & - & - \\
\hline & Spoiler failure & - & 1,72 & 2,11 & - & - & - & - \\
\hline & Brake failure & - & 1,72 & 4,23 & 2,78 & 1,85 & 9,29 & - \\
\hline & \begin{tabular}{|l|} 
Landing gear failure \\
\end{tabular} & 2,13 & 21,55 & 5,63 & 13,89 & 3,70 & - & - \\
\hline & \begin{tabular}{|l} 
Loss hydraulic power \\
\end{tabular} & - & 1,72 & 1,41 & - & - & - & - \\
\hline & \begin{tabular}{|l|} 
Loss electrical power \\
\end{tabular} & - & - & 1,41 & - & - & - & - \\
\hline & Anti-skid system failure & 2,13 & - & - & - & - & - & - \\
\hline & High speed & - & 1,72 & 7,04 & 2,78 & 7,41 & - & - \\
\hline \multirow{5}{*}{ 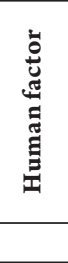 } & $\begin{array}{l}\text { Inadequate crew } \\
\text { competence }\end{array}$ & 17,02 & 30,18 & 30,17 & 30,56 & 25,93 & 35,45 & 6,67 \\
\hline & \begin{tabular}{|l} 
Inadequate ATC service \\
\end{tabular} & 4,26 & 0,86 & - & - & - & 9,29 & 13,33 \\
\hline & Inadequate maintenance & - & 2,59 & 2,11 & 2,78 & 1,858 & - & - \\
\hline & $\begin{array}{l}\text { Incorrect loading of the } \\
\text { aircraft }\end{array}$ & 4,26 & 1,72 & 1,41 & 5,56 & 18,52 & - & - \\
\hline & Unknown causes & 38,30 & 25 & 17,61 & 2,78 & 24,07 & 15,20 & 46,67 \\
\hline
\end{tabular}


For visually the many potential causes defined for each accident fishbone diagrams were constructed; the causes represent the backbone of the fish to each accident. These diagrams are shown in the following figures (Figs. 2-8).

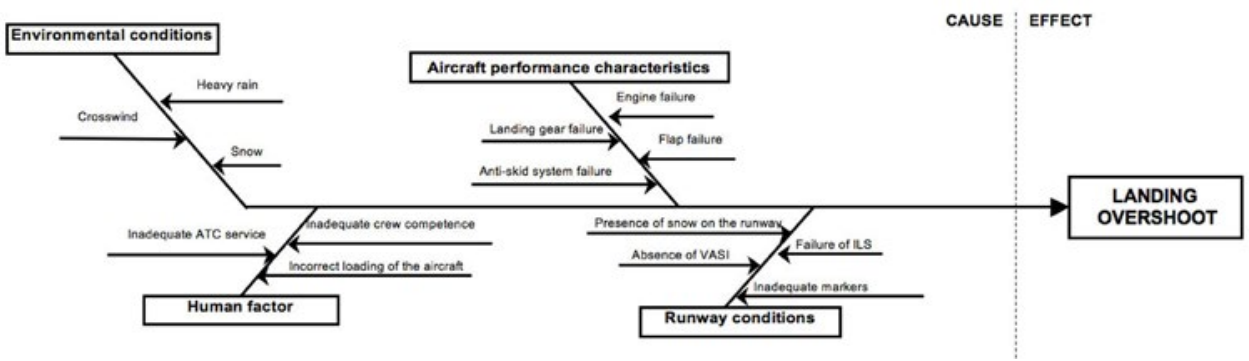

Fig. 2.

Landing Overshoot Fishbone Diagram

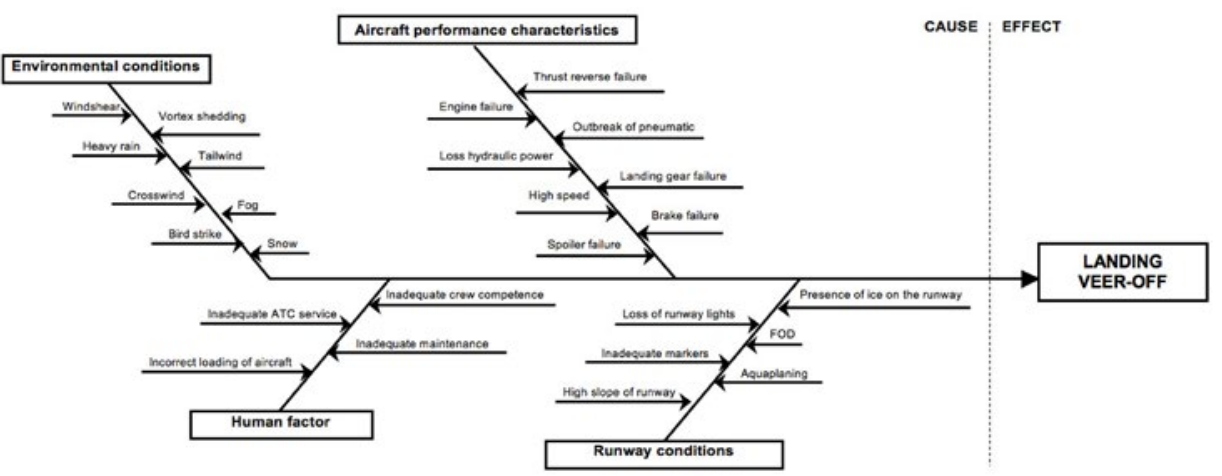

Fig. 3.

Landing Veer-Off Fishbone Diagram

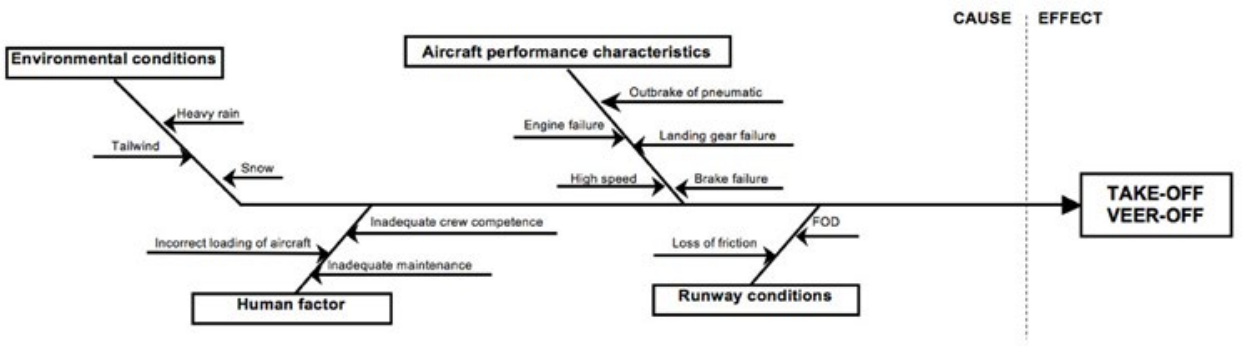

Fig. 4.

Take-Off Veer-Off Fishbone Diagram 


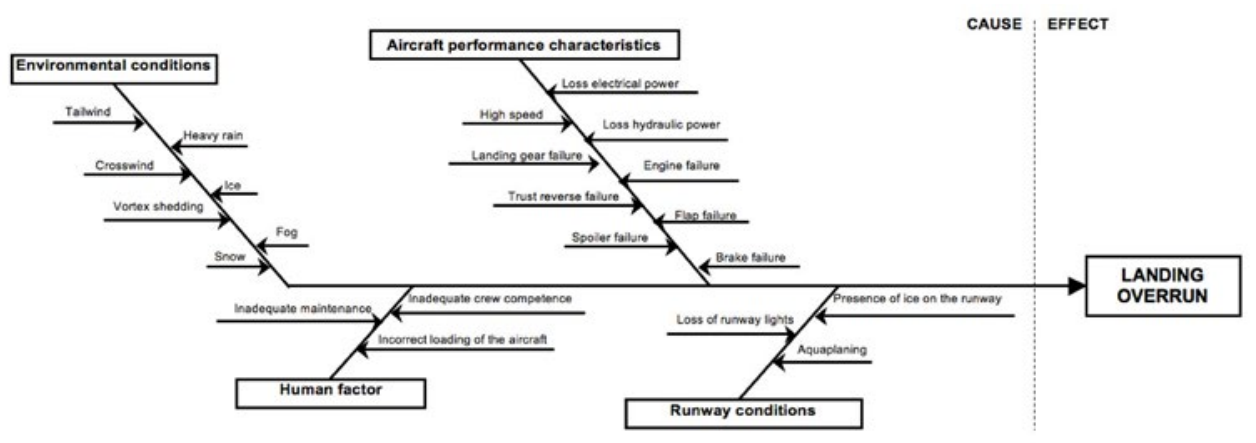

Fig. 5.

Landing Overrun Fishbone Diagram

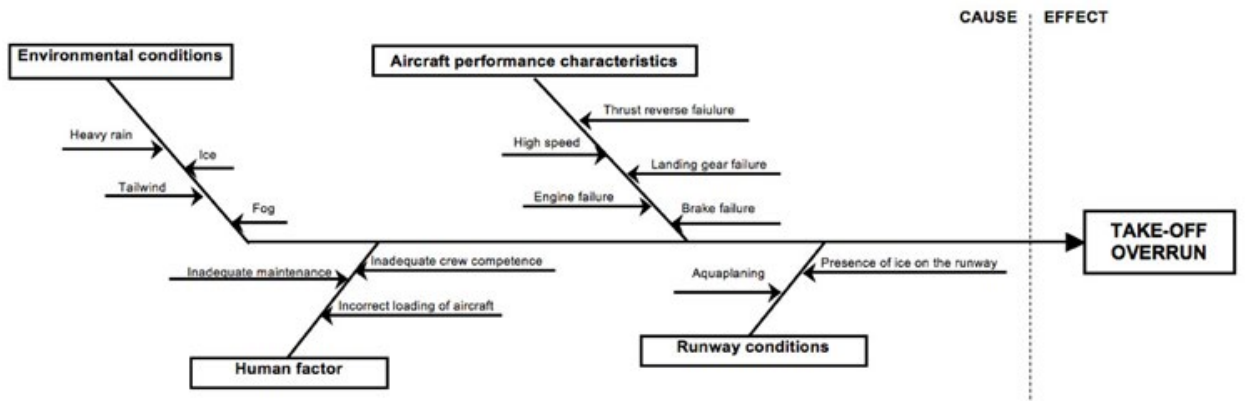

Fig. 6.

Take-Off Overrun Fishbone Diagram

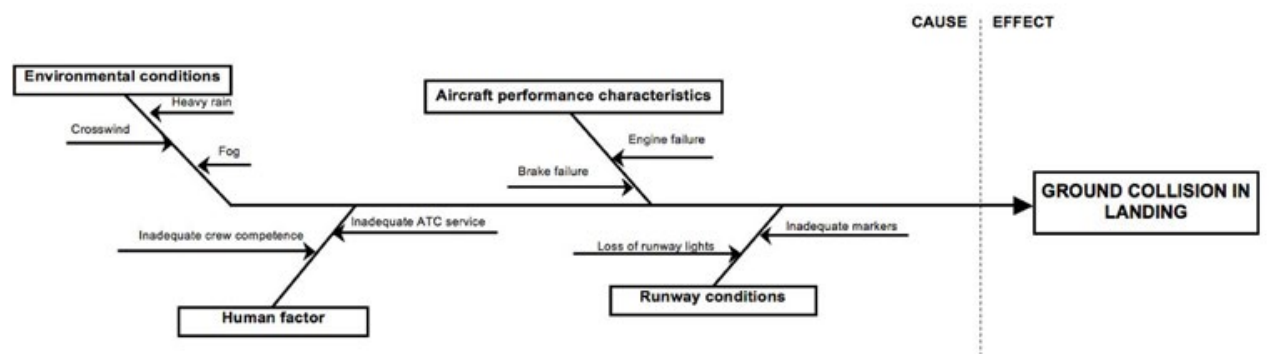

Fig. 7.

Ground Collision with other Aircraft in Landing Fishbone Diagram 


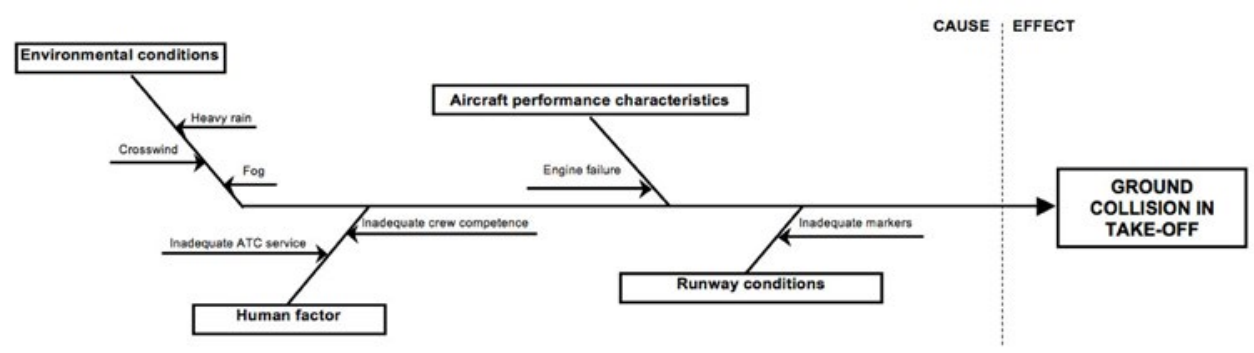

Fig. 8.

Ground Collision with other Aircraft in Take-Off Fishbone Diagram

\subsection{Hazard Probability Assessment}

Any quantitative risk assessment requires an analysis of the probability of each of the potential events that may occur.

In the present risk assessment procedure the probability of each hazard is proportional to the cumulative probability of the causes identified for the hazard, so in order to calculate the hazard probability it has been used the Total Probability Theorem (Eq. (1)). Therefore:

$P(E)=\sum_{i=1}^{n} P\left(E \mid C_{i}\right) \cdot P\left(C_{i}\right)$

Where:

$P\left(E \mid C_{i}\right)=$ probability that, in presence of the cause $i$ (e.g. heavy rain), the hazard (e.g. landing overrun) will occur (Conditional probability).

$P\left(C_{i}\right)=$ probability that the cause $i$ (e.g. heavy rain) will occur.

$P\left(E \mid C_{\mathrm{i}}\right) \cdot P\left(C_{i}\right)=$ probability that the cause $i$ will produce the hazard.

The authors believe that the $P\left(E \mid C_{i}\right)$ assessment must be carried out by analyzing of the National data for the causes belonging to environmental and runway conditions and by analyzing the International data for the causes belonging to the aircraft performance characteristics and human factors.

Using the databases it is possible to assess the frequency at which each cause determines a hazard. We assume the frequency as the value of probability (Eq. (2)). Therefore:

$P\left(E \mid C_{i}\right)=N_{E} / N_{M C}$

Where:

$N_{E}=$ number of events occurred during takeoff or landing, in a definite period, generated by the cause $i$.

$N_{M C}=$ number of take-offs or landings, in a definite period, occurred in presence of the cause $i$.

Through the Eq. (2) the probability that, in presence of the cause $i$, the hazard will occur it is not calculated for a specific airport, in fact report $P\left(E \mid C_{i}\right)$ to the single airport requires a large amount of data, in order to be statistically significant. Since the available data is quite poor, we refer $P\left(E \mid C_{i}\right)$ generally to National airports. 
The probability $P\left(C_{i}\right)$ of the cause $i$ is assumed equal to the frequency whit which the cause occurred in the airport studied (Eq. (3)).

$$
P\left(C_{i}\right)=N_{M(a) i} / N_{M(a)}
$$

Where:

$P\left(C_{i}\right)=$ probability that the cause $i$ will occur in a specific airport, for causes of the environmental and runway conditions categories.

$N_{M(a) i}=$ number of take-offs or landings, in a definite period, in the airport studied occurred in presence of the cause $i$ (e.g. number of landings occurred in presence of snow).

$N_{M(a)}=$ total number of take-offs or landings, in a definite period, occurred in the airport studied.

The total number of take-offs and landings occurred in the airport and the number of flight movements occurred in presence of the causes belonging to environmental and runway conditions categories are provided by the airport management company.

The probability of the causes belonging to the aircraft performance characteristics category is not dependent on the airport where they occur, so data about failures, for each type of aircraft, should be provided by airlines companies.

Considering the composition of the traffic flow of an airport which is to be the object in the study, based on data provided by the airlines companies it must realize a valid process of weighting. So, in this case, the
Eq. (3) for $P\left(C_{i}\right)$ assessment becomes the following (Eq. (4)):

$$
P\left(C_{i}\right)=\sum_{J=1}^{n} N_{F j} \cdot N_{M(a) j} / \sum_{j=1}^{n} N_{M(a) j}
$$

Where:

$P\left(C_{i}\right)=$ probability that the cause $i$ will occur, for causes of the aircraft performance characteristics category.

$N_{F j}=$ number of failures associated with the cause $i$ suffered by the aircrafts of the type $j$, in a definite period, to refer to total number of take-offs or landings, which an aircraft makes in the same period (e.g. if aircraft of type $j$ had one engine failure in 800.000 take-offs then $N_{F j}=1 / 800.000=$ $\left.1,25 \cdot 10^{-6}\right)$.

$N_{M(a) j}=$ total number of take-offs (landings), which an aircraft of type $j$ makes, in a stated period, in the airport studied.

The probability assessment of the causes belonging to the human factors category (e.g. communication misunderstanding, inadequate crew competence, airside driver competence, etc.) is very difficult.

The probable cause of more than $70 \%$ of commercial aircraft hull-loss accidents has been cited as "human error". Today, more accident/incident investigations have been focusing on the human factors in each operation during flight. This includes flight crew operations, air traffic control, ground operations, and maintenance operations.

This study doesn't take into account the category of human factor because of the absence of human factors data. 


\subsection{Hazard Severity Assessment}

In order to determine the severity of each hazard identified in step 1 , the present procedure uses the results of a previous study by the same authors (Distefano and Leonardi, 2012). This study provides the estimation of severity of the aircraft accident associated with airport operations differentiated for class of aircraft, through a methodology based on historical data contained in a database similar to that used in the present procedure.

The different classes of aircraft operations considered are:

- General aviation aircraft (GA): typically these aircraft can have one (single engine) or two engines (twin engine). Their maximum gross weight is below $14.000 \mathrm{lb}$.

- Corporate aircraft (CA): typically these aircraft can have one or two turboprop driven or jet engines (sometimes three). Maximum gross mass is up to $90.000 \mathrm{lb}$.

- Commuter aircraft (COM A): usually twin engine aircraft with a few exceptions such as the De Havilland DHC-/ which has four engines. Their maximum gross mass is below $70.000 \mathrm{lb}$.

- Transport aircraft (TA):

- $\quad$ Short-range (S-R): their maximum gross mass usually is below $150.000 \mathrm{lb}$.

- Medium-range (M-R): these are transport aircraft employed to fly routes of less than $3.000 \mathrm{~nm}$ (typical). Their maximum gross mass usually is below $350.000 \mathrm{lb}$.

- Long-range (L-R): these are transport aircraft employed to fly routes of less than $3.000 \mathrm{~nm}$ (typical). Their maximum gross mass usually is above $350.000 \mathrm{lb}$.

Fig. 9 shows the results of this study. 

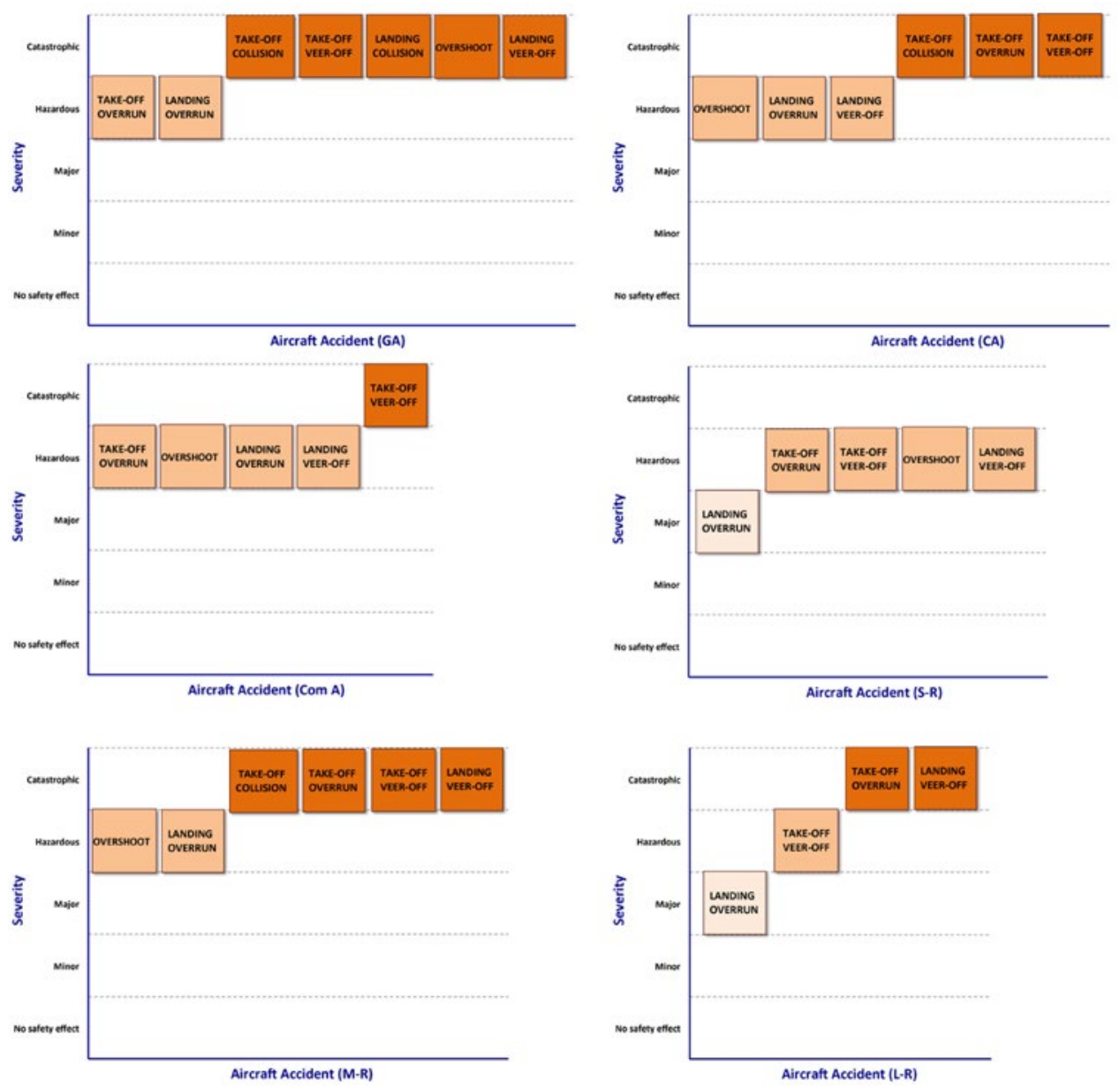

Fig. 9.

Hazard Severity for Class of Aircraft 


\section{Conclusions}

In the past, only accident or fatality data were investigated and used to measure the risk or/and safety level of airlines. This is just a reactive way to manage the aviation risk. However, commercial aviation is a complex mosaic of many varied, yet interrelated human, technical, environmental, and organizational factors that affect safety and system performance. The possible influencing factors should be included while assessing risk (Shyur, 2008).

This paper proposed a new quantitative methodology for the assessment of risk in civil aviation. In order to estimate the probability of each accident proportionally to the cumulative probability of the causes identified for the accident, it was used the Total Probability Theorem. In order to determine the severity of each hazard identified in step 1 , the present procedure uses the results of a previous study by the same authors (Distefano and Leonardi, 2012). This study provides the estimation of severity of the aircraft accident associated with airport operations differentiated for class of aircraft.

After safety risks have been assessed though the present procedure, elimination and/or mitigation must take place. This is known as safety risk mitigation. Safety risk controls must be designed and implemented. These may be additional or changed procedures, new supervisory controls, changes to training, additional or modified equipment, or any of a number of other elimination/ mitigation alternatives.

\section{References}

ACRP. 2008. Report 3 - Analysis of Aircraft Overruns and Undershoots for Runway Safety Areas, 60 p.

Distefano, N.; Leonardi, S. 2012. A qualitative risk severity assessment for aircraft accident in civil airport. 5th International Proceeding SIIV "Sustainability of Road Infrastructures", Roma, 29/31 Ottobre 2012 1-11.

FAA. 2007. Introduction to Safety Management Systems (SMS) for Airport Operators. Washington, D.C., AC 150/5200-37, 22 p.

ICAO. 2009. Safety Management Manual (SMM). Second edition. Doc 9859, 263 p.

Janic, M. 2000. An assessment of risk and safety in civil aviation, Journal of Air Transport Management. DOI: http://dx.doi.org/10.1016/S0969-6997(99)00021-6, 6(1): 43-50

Logan, T.J. 1999. Trend toward wider sharing of safety data is resisted by industry concerns, ICAO Journal, 54(1): 7-9.

Owen, D. 1998. Air Accident Investigation: How Science Is Making Flying Safer. Patrick Stephens Limited, Yeovil.

Preyssl, C. 1995. Safety risk assessment and management - the ESA approach, Reliability Engineering and System Safety. DOI: http://dx.doi.org/10.1016/09518320(95)00047-6, 49(3): 303-309.

Shyur, H.J. 2008. A quantitative model for aviation safety risk assessment, Computer \& Industrial Engineering. DOI: http://dx.doi.org/10.1016/j.cie.2007.06.032, 54(1): 34-44. 